\title{
An Empirical Study on the Adaptation and Automation of a Cancellation Test for Children
}

\author{
Renata Cascaes \\ Institute of Natural and Exact Scien
Federal University of Pará \\ Belém, Brazil \\ renatadcascaes@gmail.com \\ Suzane Santos \\ Institute of Technology \\ Federal University of Pará \\ Belém, Brazil \\ suzanesantos8@gmail.com \\ Antônio Pereira \\ Institute of Technology \\ Federal University of Pará \\ Belém, Brazil \\ apereira@ufpa.br
}

\author{
Kalill Lameira \\ Institute of Natural and Exact Sciences \\ Federal University of Pará \\ Belém, Brazil \\ kalill.lameira@gmail.com
Kelly Pinheiro
Institute of Philosophy and Human Sciences
Federal University of Pará
Belém, Brazil
kellyvalep@gmail.com

\author{
Ricardo Sarmanho \\ Institute of Natural and Exact Sciences \\ Federal University of Pará \\ Belém, Brazil \\ ricardosarmanho@hotmail.com \\ Marcelle Pereira Mota \\ Institute of Natural and Exact Sciences \\ Federal University of Pará \\ Belém, Brazil \\ mpmota@ufpa.br
}

\author{
Nelson Cruz Sampaio Neto \\ Institute of Natural and Exact Sciences \\ Federal University of Pará \\ Belém, Brazil \\ nelsonneto@ufpa.br
}

\begin{abstract}
Tests that evaluate individual strategies of visual exploration may be useful for uncovering deviations from typical development, such as autism spectrum disorder and dyslexia. One subgroup of visual exploration tests, called cancellation tests, requires the identification of specific targets surrounded by distractors. However, the lack of automated versions of these tests limits their availability to a broader audience. In the present paper, we present an automated version of a cancellation test: the cars' test. The test is designed to be used by specialists, optimizing both its application and the analysis of collected data. First, we evaluated the cars' test in a group of six to nine-years-old children enrolled in a private school, 22 children in total. Then, after some modifications based on the observations made during the first test (increase in the number of targets and distractors on the screen, for example), a second test was performed in a public school with a larger group of children, 82 participants, allowing a better statistical analysis of the collected data. The results suggest that the cars' test is useful in providing information about visual exploration strategies adopted by children and is in agreement with the results of similar tests found in the literature.

Index Terms-Cancellation test; Visual exploration; Automated testing tool
\end{abstract}

\section{INTRODUCTION}

Visual exploration is the process of finding and selecting one or more targets in a scene containing a varied number of distractors [1]. Visual exploration strategies depend on the ability to control the focus of visual attention around the scene and also the ability to inhibit the engagement of prepotent (distracting) stimuli. The performance evaluation in visual exploration generally offers measures of higher cognitive abilities [2]. The visual scan analysis of a real-time scene can help to identify the existence of individual processing strategies related to specific stages of the development of neural circuits responsible for the control of visual attention. In a typical visual exploration task, the participant looks for a specific item among a set of distractors. They indicate whether the target is present or not. If present, the applicator should count how many times the user has encountered it. We usually measure the efficiency in the task performance by the number of targets identified during a predetermined time. The number of available distractors regulates the difficulty of the task since they compete for the participant's attention [3].

The object of study of this work consists of the tests that propose the evaluation of the visual exploration such as Hooper Visual Organization Task (VOT) [4 and Test of Variables of Attention (TOVA) [5], in addition to the traditional cancellation tests. In this scenario, the cancellation tests stand out, since they involve procedures that are easy to apply, both in the clinical and school environment, besides being commonly used for neurological evaluation of visuospatial function and selective attention $[6]$. The main characteristic of cancellation tests are non-verbal, timelimited tasks, in which the individual must indicate the target stimuli (letters, random pictures, and numbers) that are distributed on a piece of paper surrounded by distractors, which should be ignored by the participant [7]. The subject being tested can mark the targets on the sheet, or the applicator can record the target stimuli pointed out by the subject elsewhere. The data resulting from the application of the cancellation test provides useful information about 
the exploration strategies of the visual environment [2].

The reading of texts depends on the adequate development of attentional strategies to scan the text and extract the meaning of words. Although dyslexia is popularly characterized by disorders in the phonological processing and grapheme-phoneme transcription, there are also many pieces of evidence of an association with problems in visuospatial processing, including the control of visual attention 8. Besides, we find evidence in the literature that there is a correlation between patterns of visual exploration along with the development and scores in tests of learning and reading 9. Previous studies with cancellation tests also indicated a close relationship between the pattern of visual exploration in the tests and the stages of cognitive development in children [10], [11].

Several cognitive functions are involved in visual exploration. It is possible to mention, for example, visual perception, attention, working memory, cognitive flexibility, and behavioral inhibition [12]. In this way, cancellation tests can help specialists in screening for childhood developmental disorders such as dyslexia 13, attention deficit, and hyperactivity disorder [14, and autism spectrum disorder [15].

There is evidence that the development of neural pathways responsible for the analytical recognition from objects' characteristics precedes the maturation of pathways associated with holistic recognition [16]. The perception of complex scenes, fluent recognition of written text, for example demands both analytic and holistic strategies [17]. The pathways for the maturation of holistic strategies accelerate from six-years-old while the adult pattern is established at nine-years-old [18. The role of this transition in child development is not yet well established. However, its understanding can have important implications for learning, particularly of reading and writing [19], and the knowledge of neurodevelopmental disorders, such as autism spectrum disorder (ASD).

Research studies suggest that the strategies of visual exploration from individuals with ASD are different from normotypic individuals in terms of population. For example, the Central Coherence Theory (CCT) proposes that individuals with ASD tend to explore the visual scene initially by focusing on parts of the whole, different from normotypic individuals, which use a holistic strategy [20]. These peculiar characteristics of visual processing associated with the relative privilege of global/local strategies can be revealed in cancellation tests. However, despite the critical applicability and smooth implementation of a cancellation test, there is a lack of accessible automated instruments available for health professionals, forcing them to use less precise and more labor-intensive mechanisms such as tests performed on paper [21].

In this context, this paper proposes an adaptation of a cancellation test originally developed at France, known as the cars' test or voitures [22]. In this procedure, the individual is instructed to point the symbols representing cars located on a paper sheet in front of them. However, these cars are scattered among other symbols (house, ball, stars, among others) that work as distractors. Then, the participant must indicate as many cars as possible within a two-minute interval. The number of correct and incorrect target stimuli identified, along with the time to complete the task, are both used to evaluate the participant's performance.

The main objective of the present work is to develop a computational tool to fully automate the cars' test and allow an efficient visualization of the data collected during the procedure. For this purpose, we implemented software based on a web platform and which allowed touchscreen interaction, based on the original French test [22]. Besides allowing a higher accuracy in data collection, the idea is that the use of a touchscreen will make the test more attractive for children since it is an interaction similar to interactions that occur with tablets and smartphones. It is worth mentioning that the program will be freely available only to qualified health professionals.

Importantly, this study is the continuation of the work started in 23. In the first study 23, we applied the cars' test to a group of six to nine-years-old students from a private school and presented a quantitative analysis of the collected data, investigating the number of targets identified, number of distractors clicked improperly, the location of the first touch on the screen, and the visual exploration strategy adopted.

Based on the observations made by specialists that followed the whole process [23], we made some modifications in the software in order to make the distribution of the symbols more homogeneous on the screen (or board). Then, in this study, we performed a second test, but this time in a public school with a larger group of children between six and ten-years-old. Furthermore, we conducted a statistical analysis to obtain more accurate conclusions.

This article is organized into eight sections. Section II discusses previous works on automated cancellation tests. Section III presents the proposed tool, detailing the implemented features and their specific purposes. The test procedures are explained in Section IV. The results of the tests performed with the volunteers are reported in Sections $\mathrm{V}$ and VI Final considerations are presented in Section VII and finally future work is discussed in Section VIII

\section{RELATED WORKS}

Due to the clinical relevance of using tests to evaluate visual exploration strategies and the growing demand for automated instruments, a review of the literature identified other works that used digital technologies for cancellation tests. We detailed the selected works in this section.

The use of computational resources to carry out visual exploration tests already dates from a specific time. For example, in the study performed by Donnely et al. [24], they presented a modified cancellation test. On a board with "O" symbols as targets and "X" symbols as distractors, the users were instructed to identify with a pen scratch 
all the "O" symbols, which were on a graphics tablet (A4 paper size). This board was connected to a computer that will receive all coordinates signaled by the patient during the test. They submitted 80 adults to this test, among which 68 had some brain injury, and 28 of them already pointed out the occurrence of visuospatial neglect during the realization of inattention tests performed previously. The authors classified the remaining users as a control group (40 users) and healthy adults without any brain injury (12 users).

The purpose of the test was to identify outcome patterns among these three groups: brain injury with visuospatial neglect, brain injury without negligence, and a healthful group without brain injury. For the authors [24], the results obtained were satisfactory in identifying visuospatial neglect through the number and location of targets not identified by the user.

The use of the tablet as a technological resource also occurs in the work proposed by $\mathrm{Wu}$ et al. [25], where a system was adapted from the cancellation test K-T 26. This application was implemented for Android tablets using the Android Software Development Kit in Java and optimized for running on different platforms. The aim of this study was to investigate the clinical utility by applying the automated cancellation test called e-CT for analysis of the cognitive behavior of individuals, as well as to evaluate the influence of daily use of computer-based devices on test performance in patients with MCI (mild cognitive impairment) and $\mathrm{AD}$ (Alzheimer's disease) and whether this use in any way influenced the results in performing the eCT tests.

The test procedure was as follows: Two stimulus panels composed of 30 symbols were displayed on the right and left of a touchscreen (10.1 inches). Participants were instructed to play stimuli on the left panel that are not identical to those on the right board. After participants have finished processing all stimuli on one screen, they should tap the "next" button to continue the test. In total, there were seven pages of stimuli, and 62 stimuli should be canceled. The time allocated to complete the test was 2 minutes.

In order to validate the use of the test in question, they compared performance results in the elderly with normal cognition (NC), patients with $\mathrm{MCI}$, and patients with AD. Results were obtained from 325 participants, aged 50 to 92 years, with an average of 75.9 years, 112 men and 213 women. The authors concluded that the performance of older adults with $\mathrm{MCI}$ and $\mathrm{AD}$ in automated tests might improve when they make more frequent use of technological devices daily. However, this behavior was not observed by the authors in healthy elderly; that is, regardless of the frequency of use, their performance in the test showed no significant difference. By measuring the correct cancellations of e-CT, it was also possible to discriminate healthy elderly from patients with MCI and $\mathrm{AD}$.
In the study conducted by Reid et al. [27], they presented a computational version of a cancellation test, where the visual exploration of healthy adults was compared to the visual exploration of adults who had a history of cranial trauma. The authors used a touchscreen as the input device. At the end of the study, they found that individuals with a history of cranial trauma presented searching patterns more disorganized than healthy controls.

The automation of a set of cancellation tests in a single computational tool was proposed by Dalmajier et al. [28]. The software, called CancelletionTools, was developed with a focus on people who had suffered a stroke and developed sensory neglect. The software is open-source and stands out for being compatible with online systems, desktops (mouse and touchscreen), and tablets. The system is characterized by collecting quantitative measures along with the test execution: the number of omissions (total and by sector); re-visitations, that is canceling a target already canceled; the distance between targets canceled consecutively, and so on. However, the complete CancellationTools package is available for download only in the desktop version and exclusively for the Windows environment while its online version (www.cancellationtools.org) is limited in functionality,

Thus, the search in the literature available on the internet found only automated cancellation test applications targeted for adults. This result suggests a lack of tests aimed at children. The present work aims to fill this gap with a system designed for children and characterized to be open source and portable, meaning that it can be used on any platform or operating system, only requiring the user to have access to a web browser.

\section{Proposed Tool}

The computational tool proposed in this work is an adaptation of the cancellation test voitures, designed in France, which has the figure of a car as a target [22]. The voitures test is applied manually on a paper sheet measuring 60 by $40 \mathrm{~cm}$, placed on the top of a table (in the horizontal plane). This size was adopted because it is the same measure of school tables used in French schools. The visual stimuli are distributed as evenly as possible on the sheet, which is divided into three unnoticeable horizontal and three vertical bands, totaling nine sectors. Each sector has 30 stimuli distractors (sun, boat, house, among others) and four target stimuli (cars) arranged randomly within each sector. In total, the voitures test is composed of 36 cars to be found among 270 distractors.

The tool was developed using HTML5, Javascript, and CSS. This version is directed at children; for this reason, some characteristics of the graphical interface were adapted. The tool has four main parts: user registration, figures presentation, cancellation test, and the report containing the results. 


\section{A. User Registration}

Before carrying out the test, it is necessary to perform the registration of essential information from the participant, such as name, age, and educational institution, together with a short socio-demographic questionnaire.

\section{B. Presentation of Symbols}

As a way to guarantee the symbols are familiar to the participants, each symbol (target and distractors) is presented individually so that the child can identify it. The symbol of a car represents the target, and the set of distractors is formed by the symbols representing the following elements: airplane, boat, teapot, house, bunny, chicken, cat, flower, tree, star, and sun. We want to emphasized that the distractors mushroom and saw, present in the original test, were excluded from this version. The symbols are represented with a black profile, so that the subject's attention is directed only to the object's shape, without the influence of color on visual exploration.

\section{Cancellation Test}

The graphical interface for the cancellation test is shown in Figure 1. We based the interface on a paper board used in the voitures test [22]. The basic structure from the original application on paper, divided into nine sectors, was maintained. However, the quantity and size of the symbols were reduced proportionally to fill the frame of a touchscreen monitor of 21.5 inches. In the end, the screen contained 27 targets (three per sector) and 154 distractors. In particular, the division into sectors is difficult to understand, but can best be seen in Figure 2 The selection of symbols can be performed by a mouse or by touching the screen.

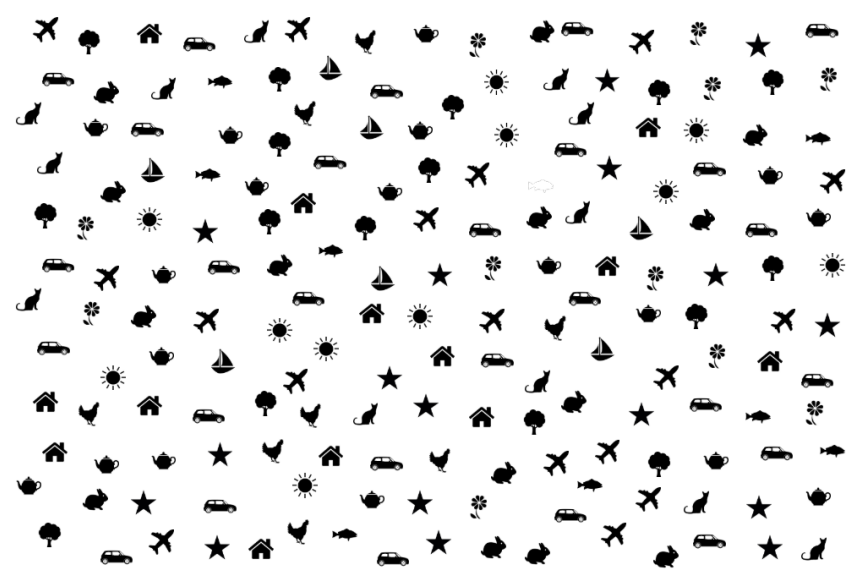

Fig. 1: Automated cancellation test screen.

\section{Report with Results}

The most significant difference between this tool, the tests performed manually, and the other automated tests found in the literature is the range of data collected and how the results are reported. The report's goal is to enable

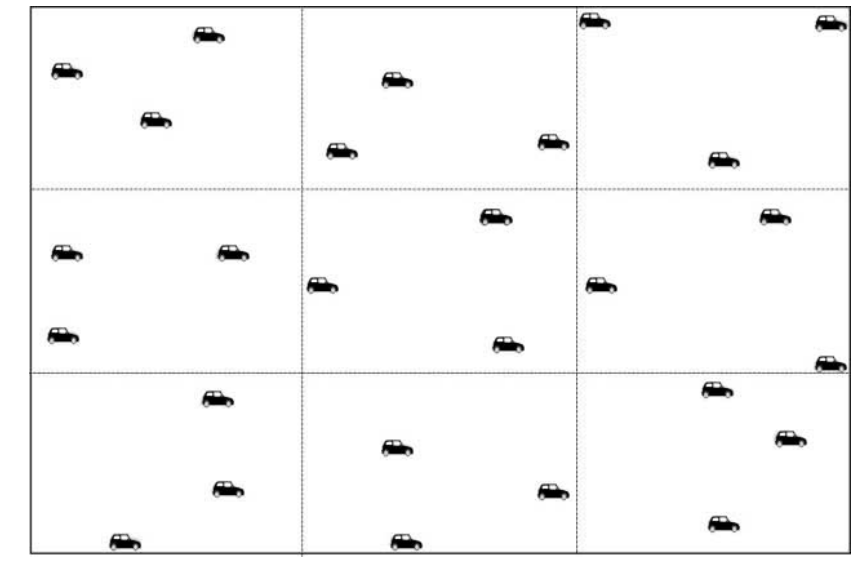

Fig. 2: Disposition of targets in each sector of the board.

the specialist to perform efficient analysis of the visual exploration strategy of the child with minimum effort.

An example of the main result generated after performing the cancellation test is shown in Figure 3 In this case, we generate a directed graph from the sequence of symbols selected by the participant in order to allow, among other things, a fundamental understanding of the visual exploration strategy adopted by the participant.

In Figures 3 8-10, the nodes of the graph are the chosen symbols, and their labels show the order of selection. The green color indicates that the chosen symbol is a car, and the red color indicates the choice of a distractor. The intensity of the color of the node is related to the number of times that it was chosen, the darker the color, the higher the number of times it was selected. If the node was selected more than once, the number of its first selection appears the label. For example, node 2 in Figure 3 has been selected three times, and the user can visualize such a sequence by hovering the mouse over it, through a tooltip. Another information associated with the node relates to the selfloop, that is, the node receives a specific marker if it has been selected successively, as happened with node 2 , which also received the 7 th and eighth clicks.

Besides the numbering of nodes, the direction of the edges also represents the order of choice of the symbols. The idea is that the applicator can easily visualize the path taken by the child in an attempt to identify all the targets. The thickness of the edge is proportional to the time the participant takes to select the next symbol, the thicker the edge, the more time spent between two nodes. It is possible to visualize all symbols not chosen by the participant in the report background, as in the case shown in Figure 3 . The tool allows the user to display only cars and also hide all non-selected symbols, which can be done by choosing the corresponding radio button, located above the image, as can be seen in Figure 3 . The caption of the visual scan report is shown in Figure 4.

Finally, a graphic containing information with the total time spent on the test and the time spent between clicks 


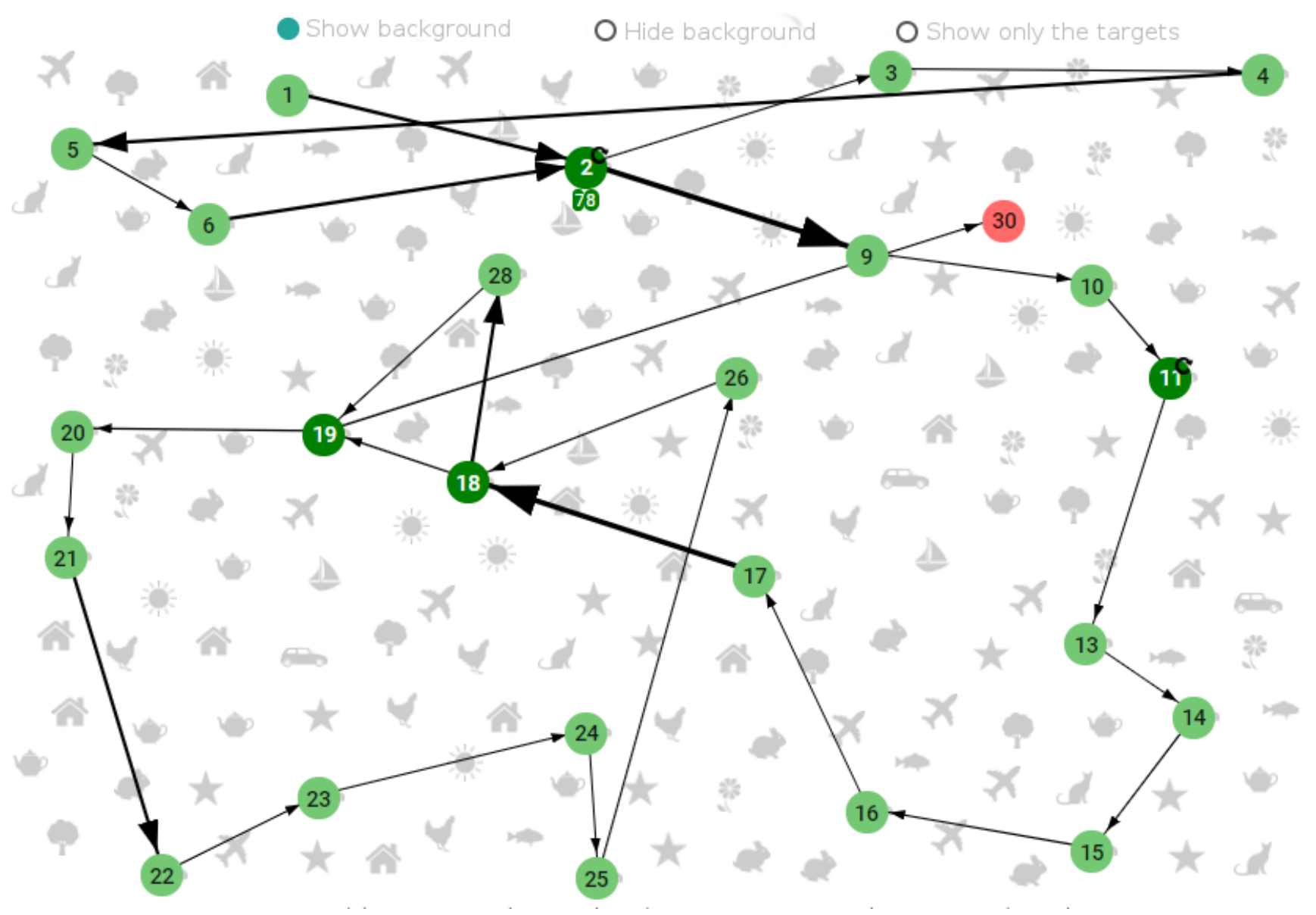

Fig. 3: Example of visual scanning graph generated by the proposed tool.
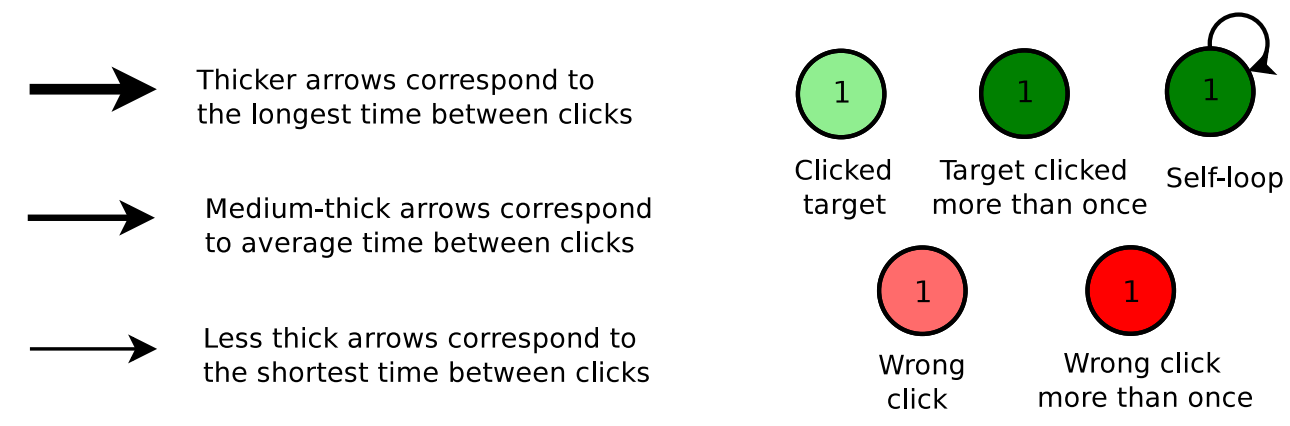

Fig. 4: Label of visual exploration graph.

is made available to the applicator. The resulting graphic of the test performed in Figure 3 can be seen in Figure 5 Note that time is presented cumulatively. Thus, in addition to knowing the time interval between target choices (green dots) and distractors (red dots), the applicator can visualize the total time of the test.

\section{TESTS PROCEDURE}

We applied the adapted and automated cancellation test to students from both a private $(\mathrm{N}=22$, Case I) and a public school $(\mathrm{N}=82$, Case II) located in Belém, Brazil. After analyzing the results obtained from Case I, we made some adjustments in the system and tested it with participants from Case II. The Research Ethics Committee approved the ethical procedures of this research of the Health Sciences Institute of the Federal University of Pará (80949617.1.0000.0018).

\section{A. Participant Selection Criteria}

We applied the following exclusion criteria for sample selection: regular use of psychotropic drugs, diagnosis of psychiatric diseases; a history of neurological and cardiovascular diseases; the presence of sensory, motor and cognitive disorders; and history of school repetition. All children 


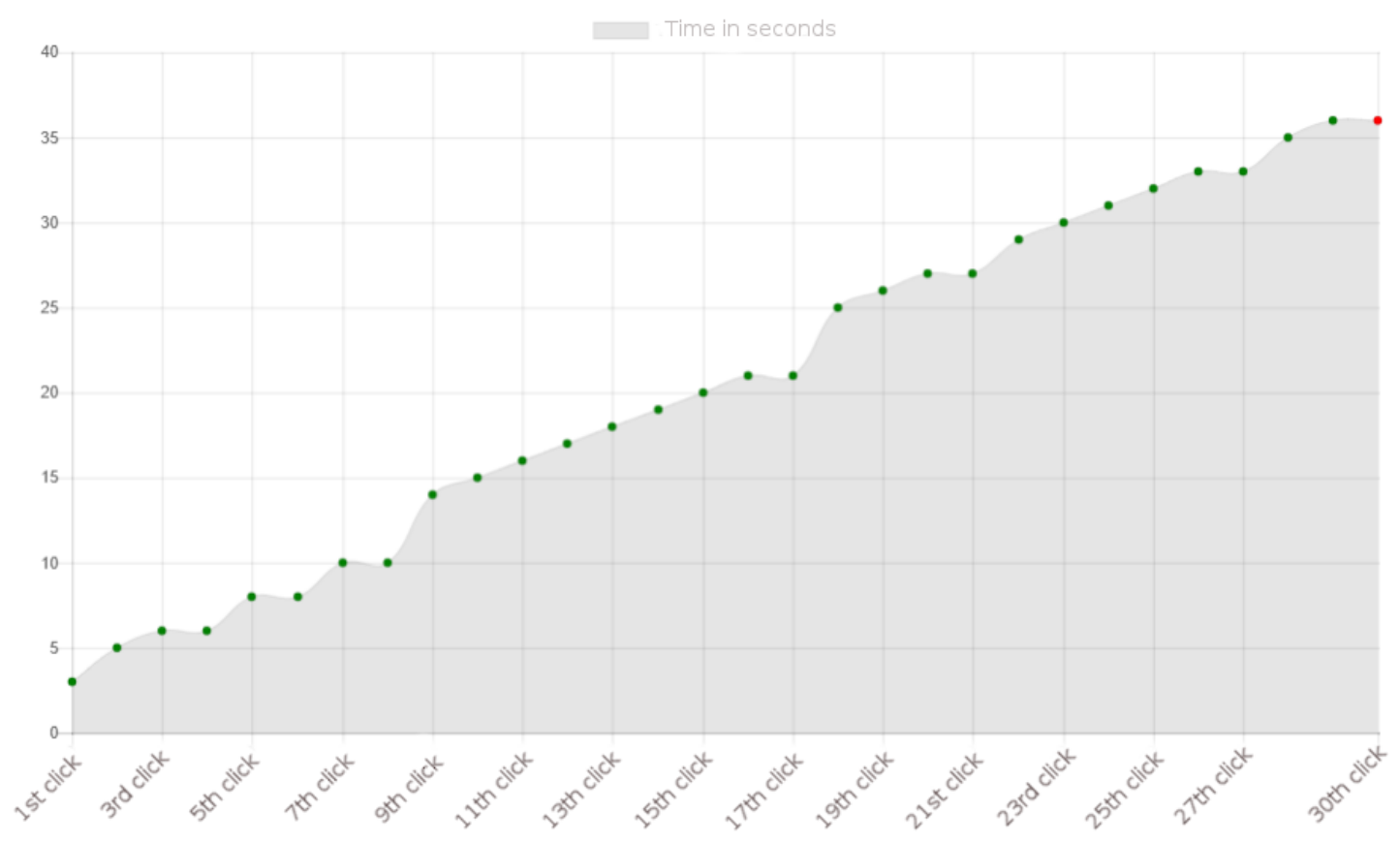

Fig. 5: Chart of the time between symbol selections.

were literate and had alleged prior contact with electronic devices, such as smartphones, tablets, and computers.

\section{B. Description of the Environment}

The tests were conducted in a well-illuminated school room and isolated from movement and noise. The software was run on a computer with Intel Core Processor (i5-4200U 1.60 GHz), 6 GB RAM, Windows 8.1 Pro operating system, and 21.5-inch touchscreen monitor.

After the registration, each child was individually led by the applicator to the experimental room and invited to sit on a chair. Later, the child was instructed to find the best position to touch the screen, located in front of them in a table with approximately $0.79 \mathrm{~m}$ of height (see Figure 6).

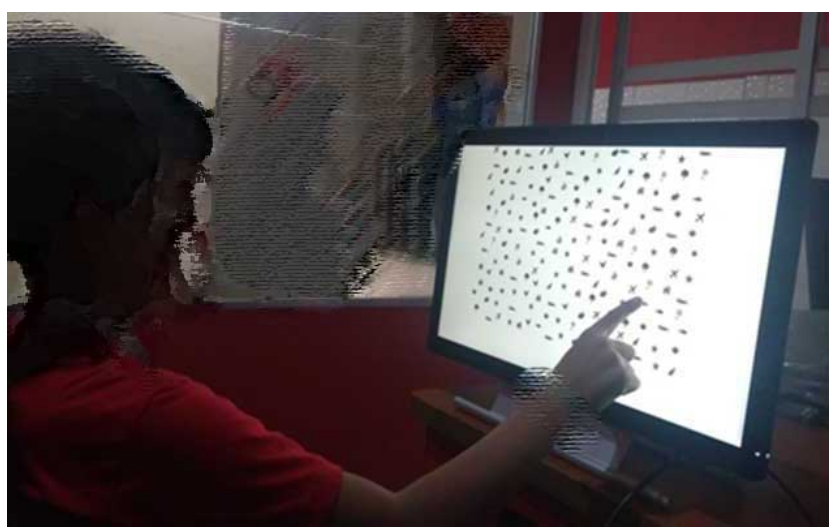

Fig. 6: Configuration for visual exploration task through a computational tool and interaction by touch. This board was applied in Case I.
The next step consisted of the individual introduction of the symbols that compose the test. After this phase, the child received the following guideline: "A picture with several drawings will be displayed in front of the monitor. You should only click on the car figures, you can click the same car several times, but the most important thing is to find all of them."

The child then performed the cancellation test by interacting with the touchscreen. The maximum time allowed to complete the task was set at two minutes. After the deadline, the process was finished automatically with a thank you message. However, in case the child reported that they found all the cars, the applicator would finish the session even before the stipulated period.

\section{CASE I: RESULTS AND DISCUSSION}

For the first test, the chosen participants $(\mathrm{N}=22)$ were between six and nine-years-old, and the parameters collected for analysis were: 1) number of identified distinct targets (IT); 2) number of selected distractors (SD); 3) number of repeated clicks on targets (RT); 4) time taken in the test (TT); and 5) latency, i.e. time between the start of the test and the selection of the first symbol (LT). The results of the visual exploration of the 22 participating children were grouped by age, as shown in Tables I and II.

The average number of identified distinct targets (IT) remained stable in the four age groups, with a small increase from seven years of age. On the other hand, analyzing the standard deviation, we can notice that the values tend to be closer to the average while the age increases. The decrease in the number of selected distractors (SD) was quite clear 
TABLE I: Average mean for Case I.

\begin{tabular}{ccccccc}
\hline Age & N & IT & SD & RT & TT(Sec) & LT(Sec) \\
\hline $\mathbf{6}$ & 6 & 19.83 & 2.17 & 9.33 & 58.67 & 5.17 \\
$\mathbf{7}$ & 6 & 22.67 & 1.17 & 23.33 & 87.50 & 1.67 \\
$\mathbf{8}$ & 4 & 24.00 & 0.50 & 12.00 & 48.75 & 2.50 \\
$\mathbf{9}$ & 6 & 22.00 & 0.00 & 7.67 & 45.67 & 1.83 \\
\hline
\end{tabular}

TABLE II: Average standard deviation for Case I.

\begin{tabular}{ccccccc}
\hline Age & N & IT & SD & RT & TT(Sec) & LT(Sec) \\
\hline $\mathbf{6}$ & 6 & 2.67 & 1.21 & 8.36 & 27.51 & 3.89 \\
$\mathbf{7}$ & 6 & 2.62 & 1.21 & 10.81 & 26.06 & 0.74 \\
$\mathbf{8}$ & 4 & 1.87 & 0.50 & 13.10 & 21.53 & 0.87 \\
$\mathbf{9}$ & 6 & 1.53 & 0.00 & 7.54 & 11.23 & 0.69 \\
\hline
\end{tabular}

from one group to another. Regarding the average of the time taken in the test (TT), we observed that the higher the age, the less time taken to find the same amount of targets. However, we observed a discrepancy in the seven-years-old group, where two children used the maximum time allowed for the test (the only ones in the whole sample) and also clicked on the same targets several times. Lastly, the latency (LT) improved from seven years of age and remained stable in the remaining age groups.

\section{A. Location of the First Symbol}

In order to verify the screen location where the children began their visual exploration, i.e., in which region the first symbol was selected, we followed the strategy of dividing the cancellation board into nine invisible (to the child) sectors. The sector where each child chooses the first symbol can be seen in Figure 7

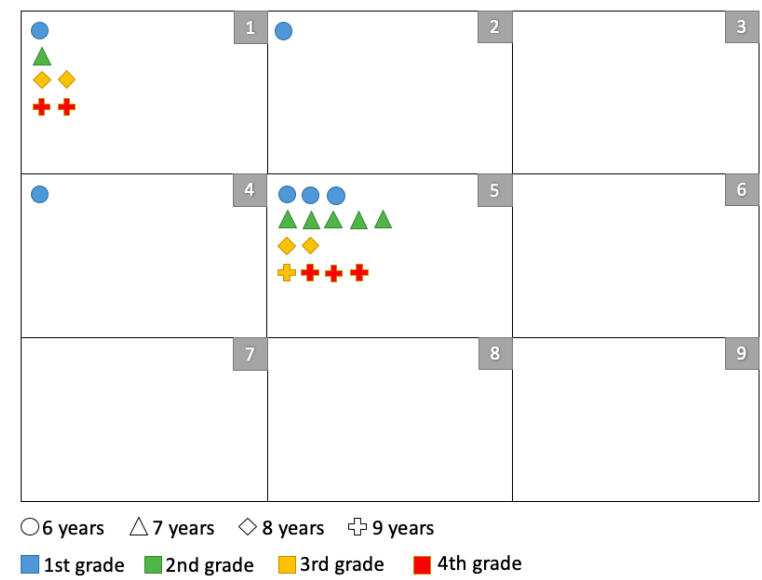

Fig. 7: First identified symbol for Case I.

At all ages and primary school grades, we can notice that most children began their visual exploration at the central sector \#5. Another point that draws attention is the number of children who started the search at sector \#1, located in the upper left corner, a value that grows as both age and school grade increase. We also noticed this tendency in other studies, and it is associated with the level of the child's reading competence 22].

\section{B. Strategies of Visual Exploration}

Analyzing the order of car identification, we tried to verify the existence of some strategy adopted by the child to find the targets and, if so, what this method would be. In this work, were adopted the criteria of linear and circular exploration defined in [22]. The analysis of the visual strategy presented here was based solely on the click orders performed by the participants.

For the circular visual exploration strategy, one of the considered criteria refers to the need to respect the direction of rotation from one sector to another on the board. Thus, only movements that share the same direction from one sector to another are considered valid. When it comes to the movements within the same sector, they are automatically validated without taking into account the direction of rotation, because they are very close cars. An example of a circular strategy can be seen in Figure 8

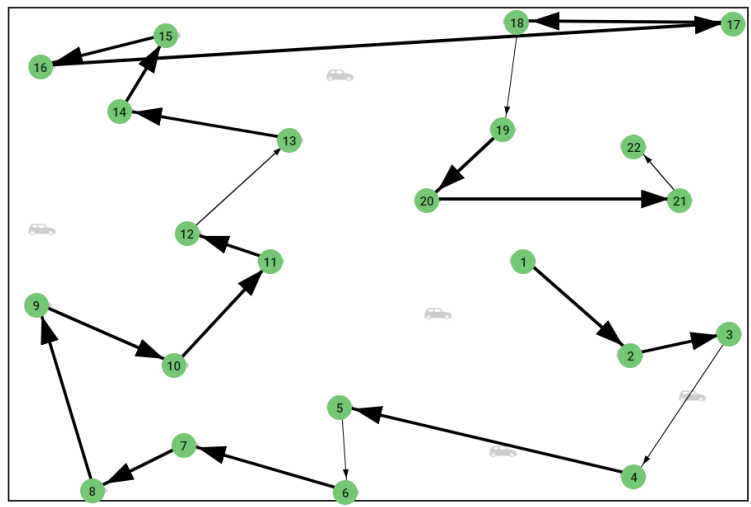

Fig. 8: Example of circular visual exploration.

The linear strategy is associated with trajectories organized in a sweeping direction from one end of the screen to another. The lines drawn to connect the markers should succeed each other from left to right (and vice-versa) for a horizontal linear strategy, or from top to bottom (and viceversa) for a vertical linear strategy. An example of horizontal linear visual search is presented in Figure 9 .

In graphs where it was not possible to identify either linear or circular search patterns, the strategy was categorized as undefined. An example of a graph in this situation is presented in Figure 10

It is important to emphasize that framing visual exploration in a single strategy is a somewhat subjective process 22. For this reason, the graphs with the visual exploration of the 22 children were analyzed individually by a group of six "blind" judges. The results can be seen in Figure 11. For the sake of simplicity, we will not distinguish between horizontal and vertical linear strategies; in other words, both will be considered just linear. In the information visualization technique shown in Figure 11 , the 


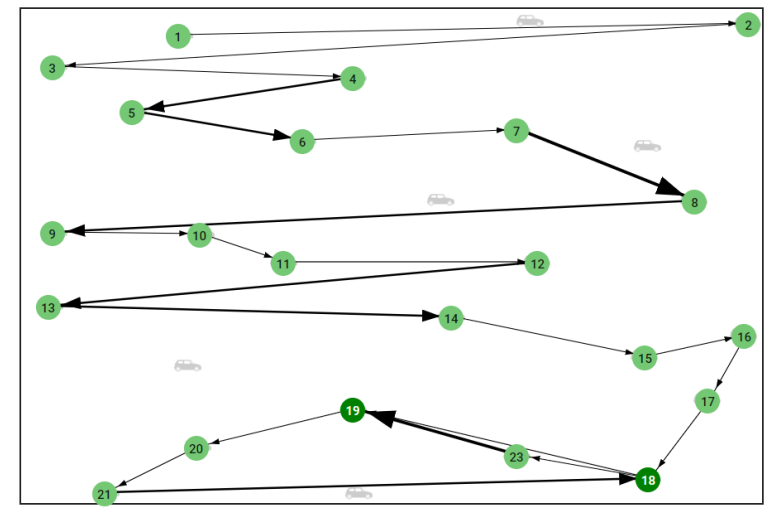

Fig. 9: Example of linear visual exploration.

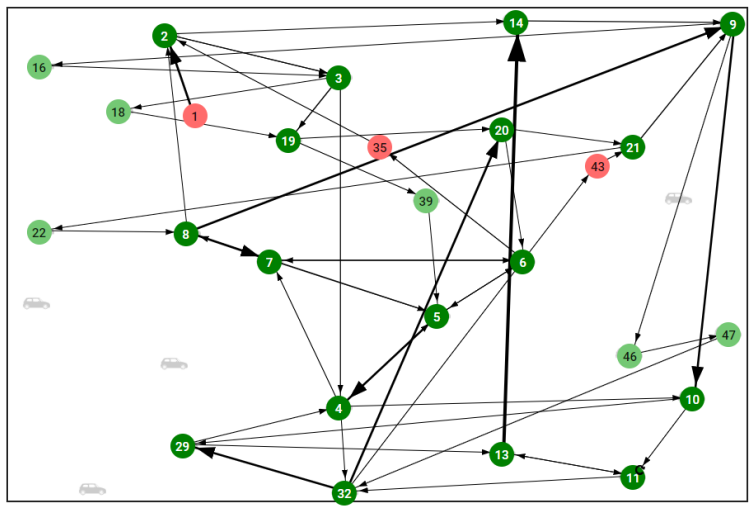

Fig. 10: Example of undefined visual exploration.

variables are assigned to parallel vertical axes. In this case, the first axis represents the age range of the participants (6 to 9 years), the central axis assumes the types of the strategy adopted by the users (circular, linear or undefined) and the third axis corresponds to the school grades in which the users are attending. We separated the analysis presented in this article into strategy vs. age and strategy vs. school grade. Regarding the linear strategy, we can conclude that it is generally adopted by the group of older children and children in more advanced grades, whereas younger children and early grades are still unable to choose a single strategy, so they have a majority present an indefinite form of visual exploration. To reinforce this statement, we can see in Figure that all nine-year-olds adopted a strategy, either linear or circular. The same occurred with children in the fourth grade.

To sum up, half of the children adopted the circular strategy $(\mathrm{N}=11)$, followed by undefined $(\mathrm{N}=7)$ and linear $(\mathrm{N}=4)$ strategies. It was also verified that the starting point and the visual search strategy are interrelated. In all, approximately $79 \%$ of the children who started exploration by the center adopted the circular exploration strategy, while almost $67 \%$ who started with the sector located in the upper left corner performed the search linearly.

Although statistical analyses are highly relevant to val-

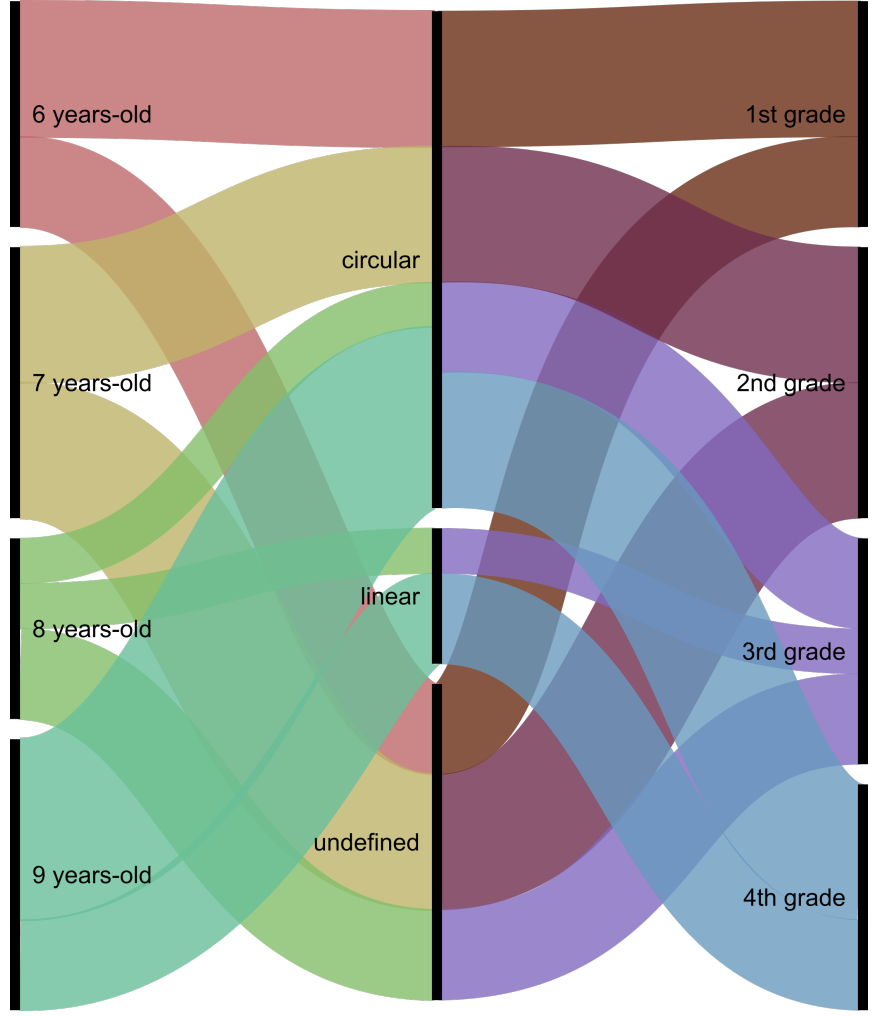

Fig. 11: Identification of the strategy adopted by the children according to age and grade for Case I.

idate specific analyzes, we were unable to perform this type of evaluation in Case I due to the small sample size. The groups of participants did not have enough samples to validate the conclusions or perform analyzes related to grade or age, making this type of analysis unfeasible.

\section{CASE II: RESULTS AND DISCUSSION}

After analyzing the results obtained from Case I, questions about the test difficulty and the symbols distribution on the board were raised by the group. Then, in an attempt to answer these questions and for experimental purposes, we decided to increase the number of participants and also the number of cars (targets) and distractors on the screen. A decisive factor in increasing the number of symbols was improving the homogeneity since, in the previous configuration, both applicators and specialists noticed an unwanted separation of the symbols, which may have influenced the strategy adopted by the child.

Therefore, the main difference between Case I and Case II is the number of symbols displayed on the screen. The cancellation test configuration used in Case II has 36 targets (four per sector, the same amount found in the original voitures test) and 206 distractors. The increase in the number of targets can best be seen in Figure 12.

The final application board can be seen in Figure 13 Note that, compared to Figure 6 the size of the symbols was somewhat reduced, the spacing between them is decreased, 


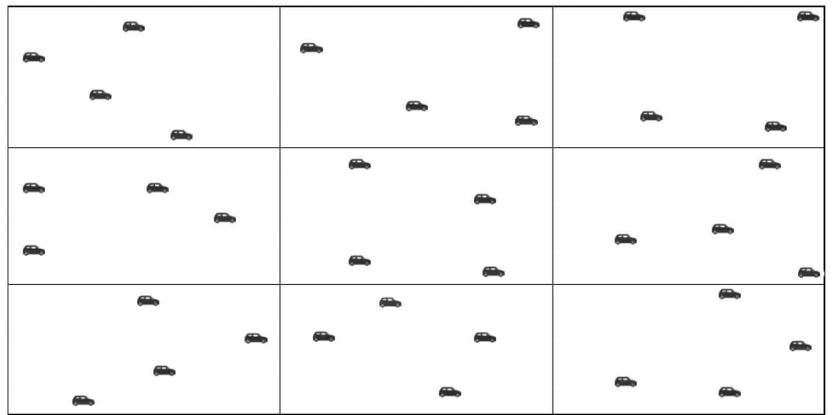

Fig. 12: Disposition of the targets for Case II.

and there are no more blank spaces on the sides of the screen.

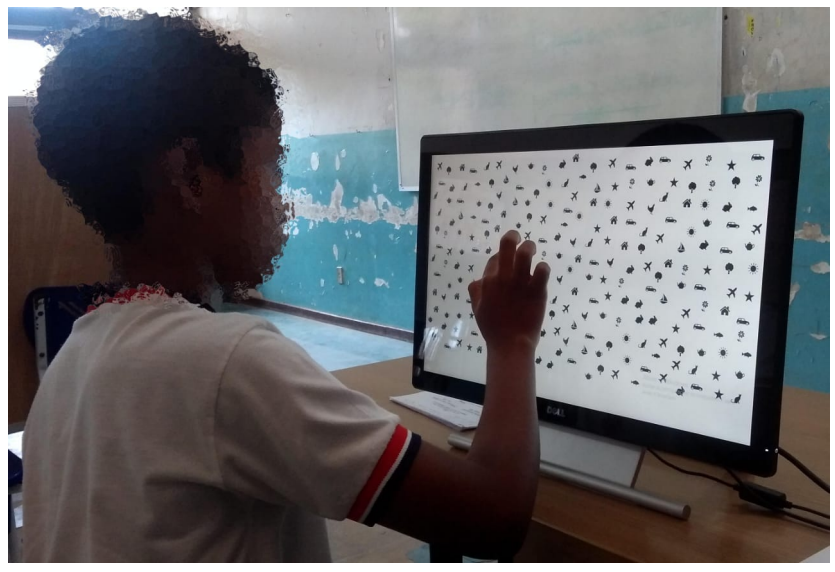

Fig. 13: Example of the board applied in Case II.

In total, 82 children between six and ten-years-old were selected to participate. The parameters collected for analysis were: 1) the number of identified distinct targets (IT); 2) the number of selected distractors (SD); 3) number of selected targets (ST); 4) time the child took in the test (TT), and 5) latency (LT). The results were grouped by age, as shown in Table III.

TABLE III: Average mean of the results for Case II.

\begin{tabular}{ccccccc}
\hline Age & N & IT & SD & ST & TT(Sec) & LT(Sec) \\
\hline $\mathbf{6}$ & 15 & 27.07 & 1.00 & 46.93 & 77.67 & 4.40 \\
$\mathbf{7}$ & 12 & 27.00 & 0.67 & 50.25 & 71.92 & 4.00 \\
$\mathbf{8}$ & 14 & 26.14 & 0.50 & 38.57 & 53.57 & 3.36 \\
$\mathbf{9}$ & 24 & 28.21 & 0.17 & 36.92 & 49.21 & 2.17 \\
$\mathbf{1 0}$ & 17 & 28.47 & 0.88 & 37.59 & 52.47 & 2.94 \\
\hline
\end{tabular}

\section{A. Location of the First Symbol}

The sector where each child chooses the first symbol can be seen in Figure 14 In general, most children, for all ages and school grades, started their exploration in the central sector \#5, 46.34\% in total.

The sector \#1 was the second with the highest amount of "first symbols", with $17.07 \%$ of initial clicks. In this sector,

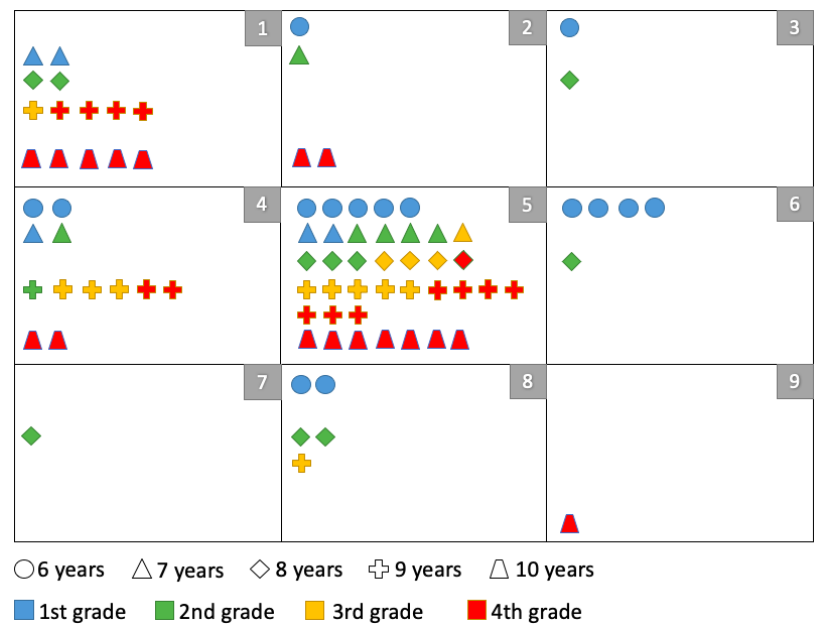

Fig. 14: First symbol identified for Case II.

we can be observe a higher concentration of older children in more advanced grades, which is expected due to the higher reading ability.

\section{B. Strategies of Visual Exploration}

Three types of strategies were considered: circular, linear (vertical and horizontal), and undefined. The results of the analysis of six external "blind" judges can be visualized in Figure 15 More than half of the children adopted the circular strategy (58.53\%), followed by undefined $(23.17 \%)$ and linear $(18.29 \%)$ strategies.

\section{Statistical Analysis}

The statistical analysis of the data aims to verify the hypothesis that the means of the number of identified distinct targets (IT), the number of selected targets (ST), and the time spent during the test (TT) differ as to age increases. Another analysis was conducted considering school grade as the independent variable (or grouping) since, in a given grade, there are children of different ages. Finally, the question of the visual exploration strategy was analyzed. The idea is to study whether older children in more advanced grades adopt better defined visual exploration strategies.

Initially, the outliers of each group were identified. The dispersion diagrams can be seen in Figure 16 . Considering age as an independent variable, we removed four outliers from the sample (the two values at nine-years-old correspond to the same child). Regarding the grouping by grade, only two outliers were excluded, both in the 4 th grade.

To conduct the statistical analysis the main test used was the ANOVA test [29]. It is well-known that this test requires a data set modeled by a normal distribution. Statistically, two numerical measures of form - asymmetry and kurtosis - can be used to test normality. The values for asymmetry and kurtosis between -2 and +2 are considered acceptable in order to prove normal univariate distribution [30. The descriptive statistics are shown in Table IV] In addition, Fisher's test [31] was applied to verify exploration strategies. 


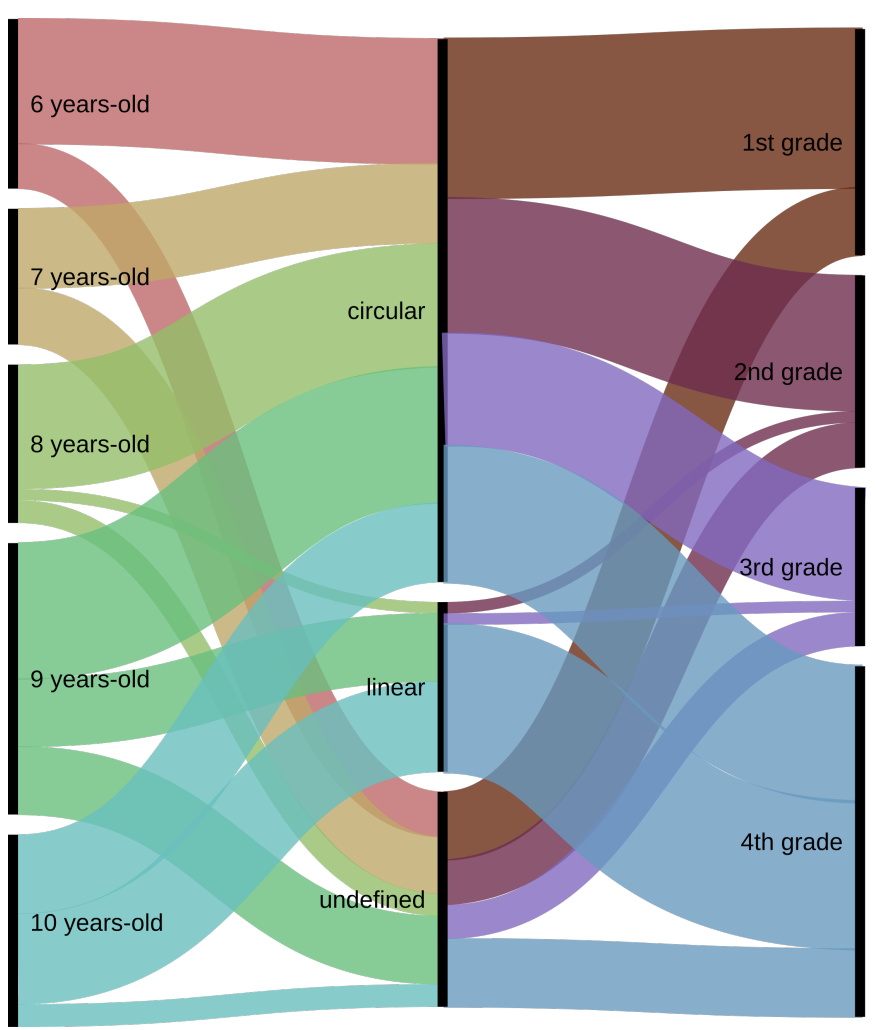

Fig. 15: Identification of the strategy adopted by the children according to age and grade for Case II.

TABLE IV: Descriptive statistics considering age and grade.

\begin{tabular}{cccc|ccc} 
& \multicolumn{3}{c}{ Age } & \multicolumn{3}{c}{ Grade } \\
& IT & ST & TT & IT & ST & TT \\
\hline Mean & 27.38 & 40.29 & 57.19 & 27.48 & 40.73 & 58.18 \\
Std & 3.91 & 14.94 & 23.60 & 3.91 & 15.09 & 24.10 \\
Kurtosis & $\mathbf{0 . 2 6}$ & $\mathbf{1 . 0 9}$ & $\mathbf{0 . 2 8}$ & $\mathbf{0 . 2 7}$ & $\mathbf{0 . 8 4}$ & $\mathbf{- 0 . 0 3}$ \\
Skewness & $\mathbf{- 0 . 6 7}$ & $\mathbf{1 . 2 1}$ & $\mathbf{0 . 9 0}$ & $\mathbf{- 0 . 6 9}$ & $\mathbf{1 . 1 3}$ & $\mathbf{0 . 8 1}$ \\
Minimum & 17 & 18 & 19 & 17 & 18 & 19 \\
Maximum & 34 & 91 & 120 & 34 & 91 & 120 \\
Count & 78 & 78 & 78 & 80 & 80 & 80 \\
\hline
\end{tabular}

1) Identified Targets (IT): Regarding the identified targets parameter, the ANOVA test showed that, on average, the age factor did not influence the number of targets identified by the participants $(F(4,73)=0.866 ; p=0.489>0.05)$. Table $\mathrm{V}$ shows the descriptive statistics.

TABLE V: Descriptive statistics of the identified targets parameter considering age.

\begin{tabular}{cccc}
\hline Age & $\mathbf{N}$ & Mean & Std. deviation \\
\hline 6 & 15 & 27.07 & 4.621 \\
7 & 12 & 27.0 & 4.328 \\
8 & 13 & 25.92 & 5.107 \\
9 & 23 & 28.0 & 2.985 \\
10 & 15 & 28.33 & 2.795 \\
\hline
\end{tabular}

TABLE VI: Descriptive statistics of the identified targets parameter considering grade.

\begin{tabular}{cccc}
\hline Grade & N & Mean & Std. deviation \\
\hline 1 & 20 & 26.90 & 4.204 \\
2 & 17 & 26.12 & 5.207 \\
3 & 14 & 28.29 & 3.474 \\
4 & 29 & 28.28 & 2.789 \\
\hline
\end{tabular}

The descriptive statistics of the targets identified by the participants of each grade are presented in Table VI The ANOVA test showed that, on average, the grade factor also does not influence the number of targets identified $(F(3,76)=1.455 ; p=0.233>0.05)$.

This parameter refers to the number of times a participant has clicked on different targets, regardless of revisiting the same destination. This result means that, on average, all participants tended to click on the same number of goals, regardless of age or grade. That is, grade and age were not decisive factors for this parameter.

2) Selected Targets (ST): Applying the ANOVA test, it was possible to verify that there is a significant difference in the average of the selected targets parameter for different ages $(F(4,73)=3.641 ; p=0.009<0.05)$. As the ANOVA test does not indicate which means are different from each other, the Tuckey test was applied. The descriptive statistics for data related to the number of selected targets grouped by age are shown in Table VII

TABLE VII: Descriptive statistics of the selected targets parameter considering age.

\begin{tabular}{cccc}
\hline Age & N & Mean & Std. deviation \\
\hline 6 & 15 & 46.93 & 19.517 \\
7 & 12 & 50.25 & 19.490 \\
8 & 13 & 37.92 & 14.779 \\
9 & 23 & 35.57 & 7.948 \\
10 & 15 & 35.0 & 7.588 \\
\hline
\end{tabular}

The Tuckey test showed that there is a significant difference only between the age pairs 7-9 years-old and 7-10 years-old, as can be seen in Table VIII

TABLE VIII: Tuckey test results for the selected targets parameter considering age.

\begin{tabular}{cccc}
\hline Ages compared & Mean difference & Std. error & Sig. \\
\hline $7-9$ & \pm 14.685 & 4.989 & .034 \\
$7-10$ & \pm 15.250 & 5.426 & .048 \\
\hline
\end{tabular}

This parameter indicates the number of times the participant has clicked on targets, considering revisits. That is, the higher the average, the more often participants clicked on repeated cars.

The descriptive statistics of the selected targets grouped by series are shown in Table IX. Applying the ANOVA test, 
(a) IT according to age

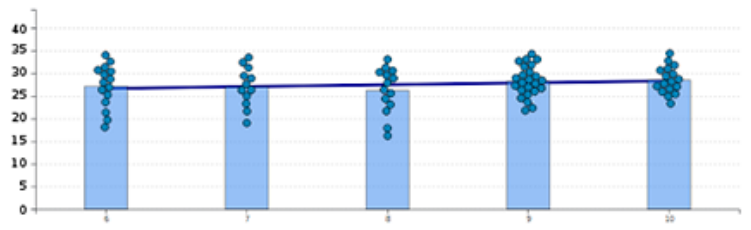

(b) ST according to age

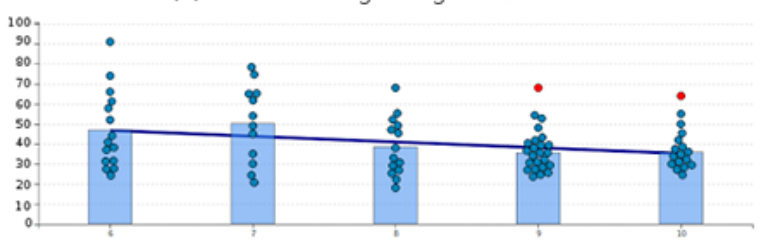

(c) $\Pi$ according to age

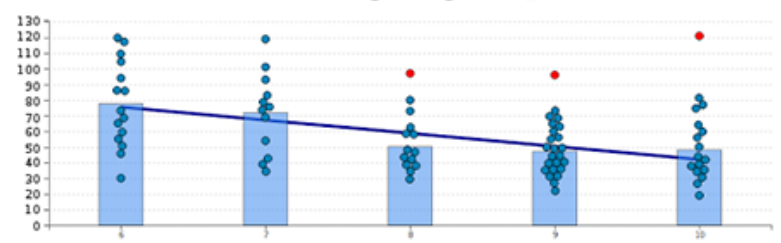

(a) IT according to grade

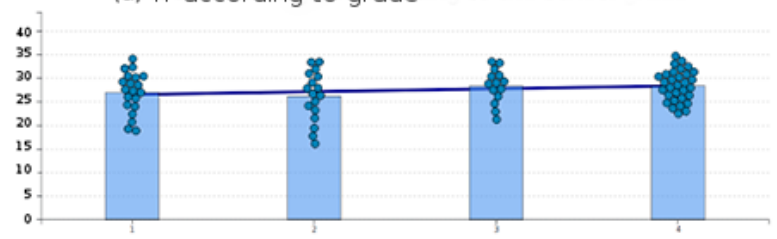

(b) ST according to grade

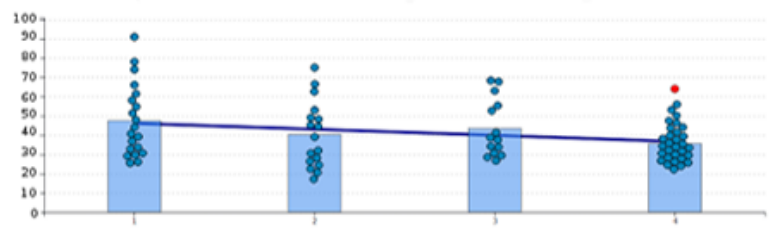

(c) $\Pi$ according to grade

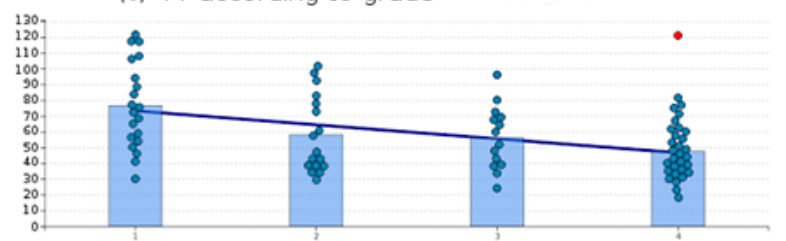

Fig. 16: Graphical representation of the relationship between the independent variables age and grade and the dependent variables: (a) the number of identified distinct targets (IT); (b) the number of selected targets (ST); and (c) the time spent during the test (TT) in seconds. The outliers are highlighted in red.

it is possible to state that, on average, the number of targets selected was significantly different between grades $(F(3,76)=3.075 ; p=0.033<0.05)$.

TABLE IX: Descriptive statistics of the selected targets parameter considering grade.

\begin{tabular}{cccc}
\hline Grade & N & Mean & Std. deviation \\
\hline 1 & 20 & 47.50 & 18.883 \\
2 & 17 & 40.24 & 17.112 \\
3 & 14 & 43.362 & 14.923 \\
4 & 29 & 35.07 & 7.750 \\
\hline
\end{tabular}

The Tuckey test, applied to verify which series presented significantly different performance, showed that, on average, the number of targets was different only between first and fourth grade $(p=0.22<0.05)$. We expected this result, given that selective and sustained attention is more developed in children of more advanced grades. This result means that, for this parameter, fourth graders showed the best performance.

3) Total Time (TT): The descriptive statistics regarding the total time parameter for each age are described in Table $\mathrm{X}$ Applying the Anova test, it was possible to verify that, on average, the time to perform the tests was significantly different between participants of different ages $(F(4,73)=8.473 ; p=0.001<0.05)$.
TABLE X: Descriptive statistics of the total time parameter considering age.

\begin{tabular}{cccc}
\hline Age & N & Mean & Std. deviation \\
\hline 6 & 15 & 77.67 & 27.463 \\
7 & 12 & 71.92 & 25.830 \\
8 & 13 & 50.23 & 15.029 \\
9 & 23 & 47.17 & 13.944 \\
10 & 15 & 46.33 & 17.727 \\
\hline
\end{tabular}

The Tuckey test showed that there was a significant direct difference between the following pairs: $6-8,6-9,6-10,7-9$, and 7-10 years-old, as can be seen in Table XI.

TABLE XI: Tuckey test results for the total time parameter considering age.

\begin{tabular}{cccc}
\hline Grades compared & Mean difference & Std. error & Sig. \\
\hline $6-8$ & \pm 27.436 & 7.590 & .005 \\
$6-9$ & \pm 30.493 & 6.647 & .001 \\
$6-10$ & \pm 31.333 & 7.314 & .001 \\
$7-9$ & \pm 24.743 & 7.133 & .008 \\
$7-10$ & \pm 25.583 & 7.757 & .013 \\
\hline
\end{tabular}

This parameter refers to how long it took participants to complete the cancellation tasks. It was expected that younger students (6 and 7 years-old) would take longer to find targets, as opposed to older students $(8,9$, and 10 
years-old). This expectation occurs because younger students still have reduced concentration and focus while older participants are in more advanced stages of apprehension, confirming expectations.

The descriptive statistics regarding the total time for each grade are presented in Table XII Applying the Anova test, it was possible to verify that, on average, the time to perform the tests was significantly different between participants of different grades $(F(3,76)=7.673 ; p=0.001<0.05)$.

TABLE XII: Descriptive statistics of the total time parameter considering grade.

\begin{tabular}{cccc}
\hline Grade & N & Mean & Std. deviation \\
\hline 1 & 20 & 76.50 & 27.295 \\
2 & 17 & 58.06 & 24.271 \\
3 & 14 & 56.14 & 19.957 \\
4 & 29 & 46.59 & 15.200 \\
\hline
\end{tabular}

Regarding the Tuckey test, it is possible to state that only one pair presented a significant difference on average: the grade pairs $1-3$ and $1-4$, as can be seen in Table XIII

TABLE XIII: Tuckey test results for the total time parameter considering grade.

\begin{tabular}{cccc}
\hline Grades compared & Mean difference & Std. error & Sig. \\
\hline $1-3$ & \pm 20.357 & 7.502 & .040 \\
$1-4$ & \pm 29.914 & 6.258 & .001 \\
\hline
\end{tabular}

The results obtained is similar to the grouping performed by age, in other words, students in the less advanced grade (first grade) were outperformed by the more advanced grade students, due to the cognitive development stage.

In a general analysis, children from 6 to 10 years-old identify on average the same amount of distinct targets, but older children need less time and select fewer targets for that. The same behavior was observed in the analysis by school year.

4) Visual Exploration Strategy: Finally, a statistical analysis was conducted to verify if the visual exploration strategy changes over the years. In order to facilitate the study, the circular and undefined strategies were grouped into a single strategy called the nonlinear. On the other hand, the vertical and horizontal linear strategies were grouped and only called linear. The frequency of occurrence of these strategies for each age is shown in Table XIV

Fisher's test applied to age samples showed that age is a characteristic that influences the type of strategy adopted by the children $(p=0.001<0.05)$. Thus, it is possible to state that most participants tended to use a nonlinear strategy. The linear pattern appears only at the highest ages.

This result was expected. Younger children respond to stimuli differently than older children. A six or seven-yearold child is more easily distracted, loses interest faster, while older children already understand instructions better and
TABLE XIV: The frequency of occurrence of each defined strategies considering age.

\begin{tabular}{cccc}
\hline Age & Nonlinear & Linear & Total \\
\hline 6 & 15 & 0 & 15 \\
7 & 12 & 0 & 12 \\
8 & 13 & 1 & 14 \\
9 & 18 & 6 & 24 \\
10 & 9 & 8 & 17 \\
\hline Total & $\mathbf{6 7}(\mathbf{8 1 . 7 \% )}$ & $\mathbf{1 5}(\mathbf{1 8 . 3 \% )}$ & $\mathbf{8 2}$ \\
\hline
\end{tabular}

can stay focused longer, completing the task faster and as in this case, adopting more sophisticated strategies.

Fisher's test was also used in the grade samples. The frequency of occurrence of these strategies for each grade is shown in Table XV

TABLE XV: The frequency of occurrence of each defined strategies considering grade.

\begin{tabular}{cccc}
\hline Grade & Nonlinear & Linear & Total \\
\hline 1 & 20 & 0 & 20 \\
2 & 16 & 1 & 17 \\
3 & 13 & 1 & 14 \\
4 & 18 & 13 & 31 \\
\hline Total & $\mathbf{6 7}(\mathbf{8 1 . 7 \% )}$ & $\mathbf{1 5}(\mathbf{1 8 . 3 \% )}$ & $\mathbf{8 2}$ \\
\hline
\end{tabular}

Fisher's test showed that the grade factor also influenced the type of strategy adopted by the participants $(p=0.001<0.05)$. This result was expected given that the choice of a strategy depends significantly on the cognitive development of users. Children in early grades are not yet familiar with the reading pattern, unlike children in more advanced grades, who already know the writing and reading pattern better and are therefore more likely to adopt a more systematic strategy, such as linear strategy.

\section{FINAL CONSIDERATIONS}

This paper presented a proposal for adaptation and automation of a cancellation test, known as the cars' test or voitures. The designed tool enables the visualization of the data collected through a graphical interface in order to facilitate and streamline the understanding of characteristics, such as type of visual exploration strategy adopted by the child, quantity, and location of the selected targets and distractors, the time between markings, among others.

After collecting and analyzing the data, it was demonstrated the great benefit in the automation of manual tests due to the amount of useful data obtained, also guaranteeing greater accuracy in the procedure. It is also important to point out that the applicator can focus its attention on personal information not collected by the tool during the test and use it to make additional behavioral analyses of the individual.

The use of technological resources, such as tablets and smartphones, is becoming increasingly common, including for children, since they have increasingly early access to digital technologies. Therefore, the children in our sample were 
enthusiastic about performing the test, mainly because of the touchscreen interaction.

After analyzing the feasibility of handling and visualizing the data generated by the tool, the two professionals who followed the whole process - from the design of the software requirements to the tests - were satisfied with the system capabilities. Thus, we consider that the proposed tool has great potential to replace manual tests for the same purpose.

Besides, the use of the tool will allow the scalability of visual exploration tests, enabling the creation of a database that can be used in further studies of visual exploration and its association with other cognitive functions, a fact that would generate a strong social impact. In general, the results obtained from Case I were consistent with those found in the literature for six to nine-year-old children, despite the adaptations made in this work, mainly in relation to i) the reduction in the size and the quantity of targets (from 36 to 27) and distractors (from 270 to 154), necessary to frame the cancellation board on a 21.5-inch monitor (the original board is 60 by $40 \mathrm{~cm}$ ); ii) change from the horizontal plane to the vertical one; and iii) change in the maximum time allowed to perform the test (from three to two minutes). The conclusions obtained from the data collected in Case I were statistically proven in Case II. As other research has also shown, students at more advanced school levels tend to hit approximately the same number of targets as younger children, but in a shorter time, by clicking a smaller number of symbols, and with more defined visual search strategies.

Some factors may have impacted the results of some individual tests. For example, because the participating audience was composed of children of varying ages, the difference in height between them required some participants to use a cushion in the chair to raise their visual range. Thus, the use of adjustable chairs, for example, is an issue that must be adopted in future applications. Another point that was also observed refers to the physical annoyance presented by certain children when interacting with the touchscreen, due to the need to keep the arm extended for the duration of tests (two minutes). An alternative way should be studied in order to reduce annoyance or eliminated it.

\section{FUTURE WORKS}

As future works, we aim to improve the tool in the following ways: make the tool parameterizable, so that the applicator can define parameters for the configuration of the test according to his/her needs. These parameters would be, for example, the duration of the test, the number of symbols and which ones will be present on the screen, the number of targets and distractors by sector, among others.

Even with an automated test, the definition of the visual exploration strategy adopted by the participant is subjective. So, another future action will be the automatization of the characterization of search strategies using pattern classification algorithms based on machine learning techniques [32], 33].

Another future goal is the simultaneous capture of ocular movement during performance of the task. Ocular movements - saccades and fixations - reveal valuable information about search patterns, which can help in the analysis of the strategies followed by the participants. This additional form of capture, through eye-tracking, integrated with the capture of touch data, could improve the identification of errors and first targets, for example.

\section{ACKNOWLEDGMENT}

This work has been supported by the Postgraduate Support Program and the Scientific and Technological Research in Assistive Technology in Brazil (CAPES / PGPTA) - Assistive Technology Announcement in Brazil and Studies on Deficiency No 59/2014 - through the project titled "Evaluation of Impacts of the Induction of a Virtual Network of Support and Learning to Individuals with Disabilities and their Families" and coordinated by Simone Souza da Costa Silva and Fernando Augusto Ramos Pontes. The authors would like to thank all the volunteers, especially those from both schools, as well as all the professionals who assisted us throughout this research.

\section{REFERENCES}

[1] J. R. Dowdall, A. Luczak, and M. S. Tata, "Temporal variability of the n2pc during efficient and inefficient visual search," Neuropsychologia, vol. 50, no. 10, pp. 2442-2453, 2012.

[2] T.-Y. Wang, H.-C. Huang, and H.-S. Huang, "Design and implementation of cancellation tasks for visual search strategies and visual attention in school children," Computers \& Education, vol. 47, no. 1, pp. 1-16, 2006.

[3] M. A. O'riordan, K. C. Plaisted, J. Driver, and S. Baron-Cohen, "Superior visual search in autism." Journal of Experimental Psychology: Human Perception and Performance, vol. 27, no. 3, p. 719, 2001.

[4] Y.-P. Wuang and C.-Y. Su, "Correlations of sensory processing and visual organization ability with participation in school-aged children with down syndrome," Research in Developmental Disabilities, vol. 32, no. 6, pp. 2398 - 2407, 2011. Disponível em: http: //www.sciencedirect.com/science/article/pii/S0891422211002770

[5] L. M. Greenberg and I. D. Waldmant, "Developmental normative data on the test of variables of attention (t.o.v.a. ${ }^{\mathrm{TM}}$ )," Journal of Child Psychology and Psychiatry, vol. 34, no. 6, pp. 10191030, 1993. Disponível em: https://onlinelibrary.wiley.com/doi/abs/ 10.1111/j.1469-7610.1993.tb01105.x

[6] S. M. D. Brucki and R. Nitrini, "Cancellation task in very low educated people," Archives of Clinical Neuropsychology, vol. 23, no. 2, pp. 139$147,2008$.

[7] C. d. O. Cardoso, R. F. C. d. Silva, and R. P. Fonseca, "Teste de cancelamento dos sinos: comparação entre duas versões," Gerais: Revista Interinstitucional de Psicologia, vol. 4, no. 1, pp. 73-80, 2011.

[8] R. F. d. Lima, C. A. S. Azoni, and S. M. Ciasca, "Atenção e funções executivas em crianças com dislexia do desenvolvimento," Psicologia em Pesquisa, vol. 7, no. 2, pp. 208-219, 2013.

[9] Y. Zhou, C. McBride-Chang, and N. Wong, "What is the role of visual skills in learning to read?" Frontiers in Psychology, vol. 5, p. 776, 2014. Disponível em: https://www.frontiersin.org/article/10. 3389/fpsyg.2014.00776

[10] D. A. Byrd, P. Touradji, M.-x. Tang, and J. J. Manly, "Cancellation test performance in african american, hispanic, and white elderly," Journal of the International Neuropsychological Society, vol. 10, no. 3, pp. 401-411, 2004.

[11] N. Lowery, D. Ragland, R. C. Gur, R. E. Gur, and P. J. Moberg, "Normative data for the symbol cancellation test in young healthy adults," Applied Neuropsychology, vol. 11, no. 4, pp. 216-219, 2004. 
[12] R. F. C. d. Silva, "Teste de cancelamento dos sinos: estudo comparativo quanto à variável escolaridade," Master's thesis, Pontifícia Universidade Católica do Rio Grande do Sul, http://tede2.pucrs.br/tede2/handle/tede/712, 2010.

[13] A. L. Cancela, "As implicações da dislexia no processo de aprendizagem na perspectiva dos professores do $1^{\circ}$ ciclo do ensino básico," Ph.D. dissertation, Universidade Fernando Pessoa, http://hdl.handle.net/10284/4262, 2014.

[14] G. Coutinho, P. Mattos, C. Araújo, and M. Duchesne, "Transtorno do déficit de atenção e hiperatividade: contribuição diagnóstica de avaliação computadorizada de atenção visual," Revista de Psiquiatria Clínica, vol. 34, no. 5, pp. 215-222, 2007.

[15] R. M. Joseph, B. Keehn, C. Connolly, J. M. Wolfe, and T. S. Horowitz, "Why is visual search superior in autism spectrum disorder?" Developmental science, vol. 12, no. 6, pp. 1083-1096, 2009.

[16] E. Kalanthroff, L. Goldfarb, and A. Henik, "Evidence for interaction between the stop signal and the stroop task conflict." Journal of Experimental Psychology: Human Perception and Performance, vol. 39, no. 2, p. 579, 2013.

[17] K. Koldewyn, P. Hanus, and B. Balas, "Visual adaptation of the perception of "life": Animacy is a basic perceptual dimension of faces," Psychonomic bulletin \& review, vol. 21, no. 4, pp. 969-975, 2014.

[18] K. Nayar, J. Franchak, K. Adolph, and L. Kiorpes, "From local to global processing: The development of illusory contour perception," Journal of experimental child psychology, vol. 131, pp. 38-55, 2015.

[19] T. Lachmann, A. Schmitt, W. Braet, and C. van Leeuwen, "Letters in the forest: global precedence effect disappears for letters but not for non-letters under reading-like conditions," Frontiers in psychology, vol. 5, p. 705, 2014.

[20] M. F. Soriano, A. J. Ibáñez-Molina, N. Paredes, and P. Macizo, "Autism: Hard to switch from details to the whole," Journal of abnormal child psychology, pp. 1-13, 2017.

[21] J. F. d. Salles, R. P. Fonseca, C. C. Rodrigues, C. B. d. Mello, T. Barbosa and M. C. Miranda, "Desenvolvimento do instrumento de avaliação neuropsicológica breve infantil neupsilin-inf," PsicoUSF Bragança Paulista, SP. Vol. 16, n. 3 (set./dez. 2011), p. 297-305., 2011.

[22] V. Barray, N. Biard, D. Gadolet, C. Guillot, D. Templier, and M. Lounis, "Voitures: analyse quantitative et qualitative des résultats d'un test d'exploration visuelle," Expériences en ergothérapie, 2002.

[23] R. Cascaes, K. Lameira, R. Sarmanho, K. Pinheiro, M. P. Mota, A. Pereira, and N. C. S. Neto, "Adaptation and automation of a cancellation test for evaluation of exploratory visual behavior," in Proceedings of the 17th Brazilian Symposium on Human Factors in Computing Systems, ser. IHC 2018. New York, NY, USA: ACM, 2018, pp. 5:1-5:9. Disponível em: http://doi.acm.org/10.1145/ 3274192.3274197

[24] N. Donnelly, R. Guest, M. Fairhurst, J. Potter, A. Deighton, and M. Patel, "Developing algorithms to enhance the sensitivity of cancellation tests of visuospatial neglect," Behavior Research Methods, Instruments, \& Computers, vol. 31, no. 4, pp. 668-673, 1999.

[25] Y.-H. Wu, J.-S. Vidal, J. de Rotrou, S. A. Sikkes, A.-S. Rigaud, and M. Plichart, "Can a tablet-based cancellation test identify cognitive impairment in older adults?” PloS one, vol. 12, no. 7, p. e0181809, 2017.

[26] Y.-H. Wu, J. de Rotrou, J.-S. Vidal, C. Jeandel, A.-S. Rigaud, E. KesseGuyot, and O. Hanon, "The kt cancellation test in the older adults: Normative data and construct validity," Aging, Neuropsychology, and Cognition, vol. 20, no. 4, pp. 429-442, 2013.

[27] D. Reid, H. Babani, and E. Jon, "Development of a computerized visual search test,” International Journal of Rehabilitation Research, vol. 32, no. 3, pp. 205-212, 2009.

[28] E. S. Dalmaijer, S. Van der Stigchel, T. C. Nijboer, T. H. Cornelissen, and M. Husain, "Cancellationtools: All-in-one software for administration and analysis of cancellation tasks," Behavior research methods, vol. 47, no. 4, pp. 1065-1075, 2015.

[29] A. Elliott and W. Woodward, Statistical Analysis Quick Reference Guidebook: With SPSS Examples, ser. Online access: Sage Sage Research Methods Online. SAGE Publications, 2007.

[30] F. J. Gravetter and L. B. Wallnau, Essentials of Statistics for the Behavioral Sciences (PSY 200 (300) Quantitative Methods in Psychology).

[31] S. Weinberg and S. Abramowitz, Statistics Using SPSS: An Integrative Approach. Cambridge University Press, 2008.
[32] I. H. Witten, E. Frank, M. A. Hall, and C. J. Pal, Data Mining: Practical machine learning tools and techniques. Morgan Kaufmann, 2016.

[33] P. Gurevich, H. Stuke, A. Kastrup, H. Stuke, and H. Hildebrandt, "Neuropsychological testing and machine learning distinguish alzheimer's disease from other causes for cognitive impairment," Frontiers in aging neuroscience, vol. 9, p. 114, 2017. 